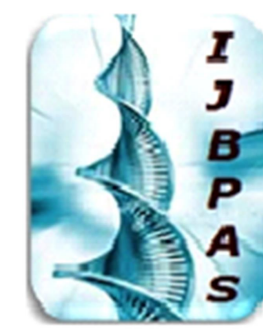

International Journal of Biology, Pharmacy and Allied Seiences (IJBPAS)

'A Bridge Betuen Caboratory and Q Q ender'

Www.ijbpas.com

\title{
AN ALL-INCLUSIVE REVIEW ON APPLICATIONS OF CASCADE MOLECULES IN PHARMACEUTICAL FORMULATION DEVELOPMENT
}

\section{SRAVYA MADDUKURI ${ }^{*}$, SAI SHREEJA ALIKETTE ${ }^{2}$, HAARIKA BALUSU ${ }^{3}$, LAKSHMI DEVI G ${ }^{4}$}

1: Assistant Professor, Department of Pharmaceutics, GITAM School of Pharmacy, Rudraram, Hyderabad, Telangana, India

2: M.Pharm, Department of Pharmaceutics, Manipal College of Pharmaceutical Sciences, Manipal Academy of Higher Education, Manipal, Karnataka, India.

3: Professor and Head of the department, Department of Pharmaceutics, Sarojini Naidu Vanita Pharmacy Mahila Vidyalaya, Tarnaka, Secunderabad, Telangana, India

4: Assistant Professor, Department of Pharmaceutics, Joginpally B.R. College of Pharmacy, Hyderabad, Telangana, India

*Corresponding Author: Dr. Sravya Maddukuri: E Mail: sravya.maddukuri23@gmail.com

Received $25^{\text {th }}$ June 2021; Revised $28^{\text {th }}$ July 2021; Accepted $29^{\text {th }}$ Aug. 2021; Available online $25^{\text {th }}$ Sept. 2021

https://doi.org/10.31032/IJBPAS/2021/10.9.1039

\begin{abstract}
Dendrimers also called arborols or cascade molecules are highly ordered, branched structures, known to possess well-defined shape, size, homogeneity, symmetry, and an extensive number of end groups and functional groups. These end groups can help in conjugating drug moieties and navigate them through the bio membranes and contribute to appreciate targeted drug delivery than existing systems in most of the cases. Dendrimer molecules or hyperbranched polymers are characterized by a core, branches-conclusive of the generation of moiety and end functional groups. This review was aimed at discussing unique properties of dendrimers possessed due to their architecture and structure, types of dendrimers, and their applications in few areas of drug delivery. Donald A Tomalia and few other prominent researchers have great contributions to this field of cascade molecules.
\end{abstract}


Starting from poly (amidoamine) (PAMAM), Poly (propylene Imine) PPI, frechet type dendrimers to micellar dendrimers, various variations of these molecules have helped the science of drug delivery as in enhancing solubility, bioavailability, achieving controlled release and sustained release, achieving the targeted release of the drug, being biocompatible, along with many unsaid effects. This review encompasses various drugs, their treatment with dendrimers, and the consequential effects produced.

\section{Keywords: Polydisperse dendrimers, Hyperbranched polymers, Arborols, Cascade molecules}

\section{INTRODUCTION}

Dendrimers, also informally called cascade molecules or arborols are highly ordered around the core and extensively branched tree-like nanostructures with outspread symmetry (as in starfish) [1]. They are known to possess well-defined shape, size, homogeneity, and monodispersity. Dendrimers originate from a category known as polymer nanoparticles [2]. The structure of a dendrimer is entirely different from that of a linear/classical polymer. Dendrimers may also be known with terms like arborols, arborescent molecules, or generally hyperbranched polymers. They consist of a globular core with hyperbranches [3]. Polyionic dendrimers may not retain determined shape and may undertake variations in size, shape, and flexibility as generations build on the core [4-6]. A typical dendrimer can be articulated [7] in terms of a

1. Central core- a focal center of the entire molecule
2. Branches from the core radially grow and decide the generation of dendrimers.

3. Terminal moieties or end groups existing on the surface of branches can be functionalized and determine the properties of dendrimer molecules.

\section{Common terms necessary to understand}

\section{the science of dendrimers:}

Hyperbranched polymers are the molecules synthesized by random polymerization of monomers [8-11] Dendrigrafts are a class of dendritic structures that possess well defined molecular structure [12]. However, dendrigrafts are built around a core which is a linear polymeric chain, unlike dendrimers which are built around a central core. Dendrons is a term used to represent part of dendrimers without a core [13]. 2 or more dendrons can be used to synthesize dendrimers by convergent synthetic methods [14]. Fréchet type dendrons, still commercially popular were synthesized convergently in 1990 by Craig Hawker and Jean Fréchet [15]. 
The frequently used term in dendrimer chemistry is the generation of a dendrimer. A generation number represents the number of branch points when assessing a molecule from the core to the surface. The higher the generation, the larger, extensively branched and more end chemical moieties are present on the surface of dendrimers [16]. Also, In the case of PAMAM dendrimers where the synthesis consists of two steps, then halfgeneration dendrimers are also recognized [17]. The central core is represented as Generation zero $\left(\mathrm{G}_{0}\right)$, From the core, through a variety of chemical reactions, branches grow and every branch thereafter will be labeled as $\mathrm{G}_{1}, \mathrm{G}_{2}, \mathrm{G}_{3}$, and so on. $\mathrm{G} 2$ PPI stands for Generation 2- polypropylene imine dendrimer, also commonly known as Dab dendrimers [18].

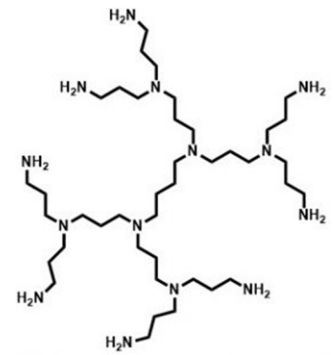

Figure 1: Generation 2-PPI dendrimer

A shell of a dendrimer is the spatial segment, space between the last branching point and the surface. Inward shells are generally referred to as the interior of dendrimer [19]. After 3-4 generations, dendrimers attain a circular shape creating an internal cavity of void space to include various drug molecules used for various applications.

\section{Dendrimers and their properties:}

Dendrimers and their extensive properties are not something very new to us, since resemblances can be found in tree roots or hyperbranched trees to gain maximum sunlight for photosynthesis to take place, or to gain maximum nutrients from the soil. Similarly, cells of lungs-bronchi/alveoli and central nervous system have the form of dendritic structures for the benefit of maximum surface area for transfer of oxygen into the blood and large assimilation and exchange of information respectively. By this dendritic pattern, augmentation of the functions of molecules can be greatly achieved. Properties of dendrimers can be categorized for our understanding into:

Pre formulation improvements: Stability, Solubility, storage [20-21]

Formulation phase improvements: Dissolution, drug release, stability in intestinal and gastric fluids, targeted drug delivery, minimization of side effects, permeation improvement in transdermal drug delivery of many drugs.

Below mentioned are a few of the exceptional properties owned by cascade molecules:

\section{High solubility and miscibility:}


This property of dendrimers can be majorly attributed to the presence of a ubiquitous number of end functional groups which result in high solubility, miscibility, and reactivity. For example- A Fréchet type dendrimer consists of carboxylic end groups on the surface increases surface functionality and also aids in the solubility of hydrophobic entities [22]. Also, Dendrimer's solubility is greatly dependent on the type of surface functional groups. It is observed that the presence of many terminal groups is responsible for the high solubility and reactivity of dendrimers, possessing both hydrophilic and hydrophobic groups. Ionic interactions, hydrogen bonding, hydrophobic interactions are a few of the interactions responsible for enhanced solubilization of poorly soluble drugs. $\mathrm{pH}$ conditions and the amount of dendrimer used in solubilization have a great say in efficiency. Once dendrimer entraps/solubilizes a hydrophobic molecule, this dendrimer-drug complex can also be used to enhance drug dissolution, stability, and bioavailability

\section{Electrostatic Interactions:}

When the terminal groups on the surface of a dendrimer are charged, the surface behaves as a polyelectrolyte (polyelectrolytes are polymers whose repeating units bear an electrolyte group) and thereby attract oppositely charged molecules [23]. To quote a few, these types of interactions may be seen as electrostatic molecular recognition procedures seen between polyelectrolyte dendrimers and charged species such as methylene blue, binding of electron paramagnetic resonance (EPR) probes, copper complexes, and nitric oxide cation radicals [24-25]. Complexation with nucleic acids forms dendriplexes. Dendriplexes are compact complexes formed by the interaction of dendrimers with deoxyribonucleic acid (DNA).

\section{Poly valency:}

A polyvalent substance qualifies to bind with different target receptors in the body and facilitate several exchanges with physiological receptors, viruses, proteins, biological cell membranes by virtue of multiple active functional groups present on the surface of dendritic molecules. The poly valency also enables multiple modifications on the surface groups of dendrimers by which different ligands can make likely bonds comparable to target agent-dendrimer as in cancer delivery, drug-dendrimer, imaging agents-dendrimer, antibody-dendrimer.

\section{Pharmacokinetic properties:}

One cannot comment on the in-vivo fate of the dendrimer carrier, though the carrier molecule's pharmacokinetics would dominate the pharmacodynamic and 
toxicologic effects of the entire drug delivery system.

Developments in the field of nanoscience have always been lacking accurate and precise predictability of pharmacokinetic parameters of nano-drug delivery systems and nanodevices once they enter the human body. One of the supremacies of nano-drug delivery systems is that they provide targeted drug delivery via the enhanced permeation and retention effect (more commonly known as the EPR effect). Pharmacokinetic parameters of these nanosystems can be determined by extensive testing in animals which is not only tedious but time-consuming. The pharmacokinetic behavior of dendrimers is influenced by properties of dendrimers such as composition, size, surface functionality, structural flexibility, and generation of a dendrimer. An easy-to-use web service and database can be found at the endpoint-

http://biosig.unimelb.edu.au/dendpoint.

which can be made use for information on most of the drug-dendrimer pharmacokinetic behavior.

\section{Monodispersity:}

Dendrimers are special polymers with a uniform structure and well-defined molecular weight resulting in a monodisperse drug delivery system [26]. The mono-dispersity of dendrimers can be confirmed by High-performance liquid chromatography (HPLC), Size-exclusion chromatography $\quad$ (SEC), $\quad$ Mass Spectroscopy, Transmission electron microscopy (TEM), gel electrophoresis.

There are mainly two factors that affect the degree of monodispersity

I. Dendrimer bridging

II. Incomplete removal of ethylenediamine at each generation sequences

The applications of dendrimers as a carrier or excipient depend on how effectively it is delivering the drug to the target site, it is based on how effectively the pharmacokinetic properties of dendrimers are achieved [27]. Selection of a dendrimer should be done keeping in mind the dose at which maximum therapeutic effect and minimum toxicity is produced.

\section{Unimolecular micelles:}

Due to the presence of hydrophilic surface groups and hydrophobic internal cavities, the properties of unimolecular micelles can be credited to dendrimers. This property enables cascade molecules to be used as nanocarriers to increase solubility and as well oral bioavailability of poorly soluble entities [28]. Unimolecular micelles accumulate intracellularly, making cascade molecules suitable vehicles of drugs and can act as trouble-shooter for the problem of drug resistance developed in many cases, 
for instance- Multidrug-resistant

tuberculosis.

\section{Chemical and physical stability:}

Hyperbranched polymers have a unique architecture that gives them excellent stability against chemical and physical stimuli, which will give stable complexes of drugs with dendrimer [29].

\section{Self-assembly:}

Self-assembly into vesicles and micelles is yet again an outstanding property of arborols. Self-assembly is best explained by Janus dendrimers which were prepared by scientist Fréchet et al. Self-assembly property is used in various bioinspired applications like controlled drug release property by external triggers.

\section{Covalent conjugation strategies:}

The coupling of small molecules to polymeric scaffolds by covalent linkages will improve pharmacological properties [30]. Conjugated dendritic assembly functions as pro-drug when internalized conjugate will be liberated to be an active drug.

TYPES OF DENDRIMERS: (Table 1)

Table 1: Types of dendrimers

\begin{tabular}{|c|c|c|c|}
\hline Type of dendrimer & Description & Synthesis method & References \\
\hline PAMAM- Poly(amidoamine) & $\begin{array}{c}\text { Core: Alkyl Diamine } \\
\text { Branches: Tertiary } \\
\text { Amines }\end{array}$ & $\begin{array}{c}\text { First synthesized by a } \\
\text { divergent method in } 1985\end{array}$ & [31] \\
\hline PPI- poly (propylene imine) & $\begin{array}{c}\text { Core: } 1,4 \\
\text { Diaminobutane, tertiary } \\
\text { tris-propylene amines, } \\
\text { primary and secondary } \\
\text { amines can be used as } \\
\text { core } \\
\text { Branches: alkyl chains } \\
\text { (hydrophobicity) }\end{array}$ & $\begin{array}{l}\text { First synthesized in } 1993 . \\
\text { Divergent approach. } \\
\text { Iterative Michael addition } \\
\text { of acrylonitrile (ACN) to } \\
\text { an amine capped with } \\
\text { ethylenediamine (EDA) }\end{array}$ & [32] \\
\hline $\begin{array}{c}\text { PEPE - polyether-copolyester } \\
\text { dendrimers }\end{array}$ & $\begin{array}{c}\text { Core: hydrophilic } \\
\text { biocompatible } \\
\text { compounds like aspartic } \\
\text { acid, butane } \\
\text { tetracarboxylic acid } \\
\text { Branches: derived from } \\
\text { PEG, Gallic acid, PEG } \\
\text { monomethacrylate. }\end{array}$ & $\begin{array}{l}\text { It uses a combination of } \\
\text { both divergent and } \\
\text { convergent approach }\end{array}$ & \\
\hline PEGylated dendrimers & $\begin{array}{l}\text { Core: multifunctional } \\
\text { core, aliphatic ester } \\
\text { Branching units: } \\
\text { polyethylene glycol } \\
\text { chains, polyethylene } \\
\text { oxide }\end{array}$ & $\begin{array}{l}\text { The one-step reaction of } \\
\text { generation } 3,4,5 \text { of DAB } \\
\text { dendrimers with amine- } \\
\text { reactive methoxy PEG } \\
\text { succinimidyl } \\
\text { carboxymethyl esters }\end{array}$ & {$[1],[65]$} \\
\hline Peptide dendrimers & Core: Peptidyl core & $\begin{array}{l}\text { Divergent or convergent } \\
\text { approach, solid-phase } \\
\text { combinatorial methods }\end{array}$ & \\
\hline $\begin{array}{c}\text { Radially layered poly } \\
\text { (amidoamine-organosilicon) } \\
\text { PAMAMOS }\end{array}$ & $\begin{array}{c}\text { Core: hydrophilic } \\
\text { polyamidoamine } \\
\text { Branches: hydrophobic } \\
\text { organosilicon }\end{array}$ & $\begin{array}{c}\text { Michael addition of } \\
\text { organosilicon acrylates or } \\
\text { methacrylates to an } \\
\text { amine-terminated } \\
\text { PAMAM dendrimer }\end{array}$ & \\
\hline
\end{tabular}




\begin{tabular}{|c|c|c|}
\hline & & $\begin{array}{l}\text { precursors or their } \\
\text { haloalkylsilanes }\end{array}$ \\
\hline Chiral Dendrimers & $\begin{array}{l}\text { Core: pentaerythritol } \\
\text { Branches: Frechets } \\
\text { aromatic-ether dendritic } \\
\text { wedges of different } \\
\text { generations }\end{array}$ & Convergent methods \\
\hline Tecto dendrimers & $\begin{array}{l}\text { Core: Ethylene diamine } \\
\text { core PAMAM G5 }\end{array}$ & Divergent methods \\
\hline Frechet type dendrimers & $\begin{array}{l}\text { Core: poly-benzyl ether, } \\
\text { conjugated fluro- } \\
\text { glucinol } \\
\text { Branching units: } 3,5- \\
\text { diallyloxybenzyl alcohol } \\
\text { Surface units: } \\
\text { carboxylic acid }\end{array}$ & $\begin{array}{l}\text { Convergent approach, } \\
\text { divergent approach }\end{array}$ \\
\hline Amphiphilic dendrimers & $\begin{array}{c}\text { Core: hydrophilic } \\
\text { aliphatic polyether type } \\
\text { interior core } \\
\text { Branching units: } \\
\text { Hydrophobic docosyl } \\
\text { peripheries }\end{array}$ & $\begin{array}{l}\text { Convergent approach and } \\
\text { Williamson etherification, } \\
\text { hydroboration/oxidation } \\
\text { steps. } \\
\text { Also, by divergent } \\
\text { approach }\end{array}$ \\
\hline Micellar dendrimers & & $\begin{array}{l}\text { Divergent/convergent } \\
\text { approach }\end{array}$ \\
\hline Astodrimer & $\begin{array}{l}\text { Core: benzhydryl amine } \\
\text { amide of L-lysine } \\
\text { Branches: naphthalene } \\
\text { disulfonic acid surface } \\
\text { groups }\end{array}$ & Divergent/ convergent \\
\hline
\end{tabular}

\section{APPLICATIONS IN DRUG} DELIVERY:

A great amount of transformation is expected in every field of science and technology in the upgrading of current materials in usage. Dendrimers in polymer science can be put into finest usage in refining the properties of substances that they combine with. Be it an antineoplastic active or a high-performance material, dendrimers revolutionize the way they act and the way they behave. A great amount of interest has been invested in delivering natural components using polymeric carriers. Dendrimers, which can form bioconjugates can be explored for encapsulation of hydrophobic compounds and delivery of antineoplastic agents. Dendrimers can be diversely made use as drug delivery devices due to the wide range of chemical modifications that can simulate in-vivo molecules, can also be made to target specific sites.

Conjugation of dendrimers with drug molecules can be achieved by [33]:

1. Covalent bond to the external surface of the dendrimer forming a pro-drug- this happens in the branching points of dendrimers. 
2. Ionic bond to charged species- this happens in the outer surface groups of dendrimers.

3. Encapsulation of drug by grouping or bonding smaller molecules or by spontaneous self-assemblage- This happens in the void spaces of dendrimers. Molecular selfassembly is common in chemistry, materials science, and biology and has been in existence even before self-assembly emerged as a discrete field of study and as a synthetic strategy.

In the case of a dendrimer,

Drug attachment to the dendrimer may be accomplished by (1) a covalent attachment or conjugation to the external surface of the dendrimer forming a dendrimer prodrug, (2) ionic coordination to charged outer functional groups, or (3) micelle-like encapsulation of a drug via a dendrimerdrug supramolecular assembly. In the case of a dendrimer prodrug structure, linking a drug to a dendrimer may be direct or linkermediated depending on desired release kinetics. Such a linker may be $\mathrm{pH}$-sensitive, enzyme-catalyzed, or a disulfide bridge. The wide range of terminal functional groups available for dendrimers allows for many different types of linker chemistries, providing yet another tunable component on the system. Key parameters to consider for linker chemistry are (1) release mechanism upon arrival to the target site, whether that be within the cell or in a certain organ system, (2) drug-dendrimer spacing to prevent lipophilic drugs from folding into the dendrimer, and (3) linker degradability and post-release trace modifications on drugs.

\section{APPLICATIONS IN SOLUBILITY ENHANCEMENT:}

Dendrimers are novel polymeric materials that find applications in diverse fields due to their exclusive structure and properties [34]. Dendrimers can be either hydrophilic, hydrophobic, or amphiphilic, they may also have hydrophilic interiors and hydrophilic exteriors which are extensively crafted for the accomplishment of unimolecular structure. Dendrimers aid in solubility enhancement, when the hydrophobic molecules get entrapped in hydrophobic cavities of dendrimers where they get solubilized. PAMAM dendrimers have extensive applications in enhancing the solubility of poorly soluble active pharmaceutical ingredients (API). Dendrimers, due to their unimolecular structure there is no account of any CMC or Critical Micellar concentration, so poorly soluble drugs are encapsulated within dendrimers, dendrimers-based carriers also enhance the oral bioavailability. 
When an anti-cancer drug, cisplatin [35], and anti-inflammatory drug, Indomethacin are encapsulated within the dendrimers, it was found that the bioavailability was increased as solubility improved, thereby, permeation through the biological membranes is also enhanced, drugs encapsulated within dendrimers have 37fold improvement in their solubility than drugs without dendrimers.

Given below are crucial parameters which decide the solubility of dendrimers:

- Generation number

- Nature of repeating units

- Core

On exposure of the drug to the carrier system, the drug may or may not encapsulate into dendrimer depends on medium properties, if drug molecules are poorly soluble in an aqueous environment and if the dendrimer is more hydrophobic then it will tend to encapsulate [8-9]. Nonsteroidal anti-inflammatory drugs like diflunisal, indomethacin, diclofenac, ibuprofen, dexamethasone, and methylprednisolone have been solubilized with dendrimer to improve its physicochemical properties and mitigate toxicity. Biocompatible dendrimers of G1.0, G2.0, and G3.0 were synthesized using PEG 600 as the core and citric acid as a branching unit. These dendritic triblock have been successfully explored for the solubilization of various non-steroidal antiinflammatory drugs (NSAIDs) such as 5amino salicylic acid (5-ASA), pyridine, mefenamic acid, and diclofenac.

\section{DENDRIMERS IN TRANSDERMAL} DELIVERY:

Most of the drugs delivered orally have poor bioavailability and in other cases show adverse effects on the GI tract (NSAIDs), so alternative routes can be opted for like transdermal drug delivery. Transdermal drug delivery maintains therapeutic blood levels for a longer period of time [36]. But the major barrier for transdermal drug delivery is skin does not permit all substances to permeate through it if the molecule has a major portion of hydrophilic groups. Dendrimers come to our rescue in such cases easing the permeation of drugs. In most of the drugs loaded with dendrimers, it not only helps in solubilization of the drug but also provides controlled release of the drug. Frequently Anticancer, antimicrobial, antiviral, antihypertensive drugs are formulated as drugs loaded with dendrimers (Table 2).

\section{DENDRIMERS IN OCULAR DRUG DELIVERY:}

Dendrimers provide proper answers to the ocular administration of complex active drugs. The ocular drug delivery system has to be non-irritating, biocompatible, sterile, biodegradable, and isotonic [29]. 
The major limitation for ocular delivery is residence time in the cornea. Pilocarpine residence time is improved by using PAMAM dendrimers which are conjugated with carboxylic and hydroxyl surface groups, these surface-modified dendrimers also augment the bioavailability of pilocarpine [30].

Table 2: Drugs loaded with dendrimers for transdermal drug delivery

\begin{tabular}{|c|c|c|c|}
\hline Drug & Dendrimer & Consequential Effect & References \\
\hline Flurbiprofen & PAMAM & $\begin{array}{c}\text { Controlled site-specific } \\
\text { delivery }\end{array}$ & {$[11]$} \\
\hline Indomethacin & G4-PAMAM & $\begin{array}{c}\text { Increased molecular diffusion } \\
\text { through the skin }\end{array}$ & Anticancer \\
\hline Cisplatin & PAMAM & $\begin{array}{c}\text { Herpes simplex virus, HIV, } \\
\text { other STDs }\end{array}$ & {$[20]$} \\
\hline Antivirals & $\begin{array}{c}\text { Poly(L-lysine) modified with } \\
\text { sulphonated naphthyl }\end{array}$ & $\begin{array}{c}\text { PAMAM } \\
\text { (BHP) }\end{array}$ & $\begin{array}{c}\text { Benign prostatic hyperplasia } \\
{[48]}\end{array}$ \\
\hline Tamsulosin & PAMAl \\
\hline
\end{tabular}

Table 3: Literature reports of few drugs-dendrimers conjugates in ocular delivery

\begin{tabular}{|c|c|c|c|c|c|}
\hline Drug & Dendrimer type & Administration & Treatment & Consequential Effect & References \\
\hline $\begin{array}{l}\text { Pilocarpine nitrate } \\
\text { and tropicamide }\end{array}$ & PAMAM G1.5-4 & Topical ocular & $\begin{array}{l}\text { Myosis and } \\
\text { Mydriasis }\end{array}$ & $\begin{array}{c}\text { Increased corneal } \\
\text { residence and } \\
\text { prolonged reduction of } \\
\text { Intra Ocular Pressure } \\
\text { (IOP) }\end{array}$ & [28] \\
\hline Carteolol & $\begin{array}{c}\text { Dendrimers with } \\
\text { phosphorous group }\end{array}$ & Topical ocular & Glaucoma & $\begin{array}{l}\text { Increased corneal } \\
\text { residence and reduced } \\
\text { toxicity and IOP }\end{array}$ & [32] \\
\hline Gatifloxacin & $\begin{array}{c}\text { Dendrimeric } \\
\text { polyguanidilyated } \\
\text { translocators }\end{array}$ & Topical ocular & $\begin{array}{l}\text { Conjunctivitis and } \\
\text { intraocular } \\
\text { infections }\end{array}$ & $\begin{array}{c}\text { Enhanced corneal } \\
\text { transport and more } \\
\text { anti-microbial activity }\end{array}$ & [34] \\
\hline Carboplatin & PAMAM G3.5-COOH & $\begin{array}{c}\text { Subconjunctival } \\
\text { injection }\end{array}$ & Retinoblastoma & $\begin{array}{c}\text { Increases half-life, } \\
\text { bioavailability, } \\
\text { reduced drug toxicity, } \\
\text { and tumor } \\
\end{array}$ & [35] \\
\hline Concanavalin A & $\begin{array}{c}\text { Porphyrin } \\
\text { glycodendrimers }\end{array}$ & $\begin{array}{c}\text { Topical- } \\
\begin{array}{c}\text { Photodynamic } \\
\text { therapy }\end{array} \\
\end{array}$ & $\begin{array}{l}\text { Intraocular tumors } \\
\text { and retinoblastoma }\end{array}$ & $\begin{array}{l}\text { Enhanced targeting } \\
\text { and reduced toxicity }\end{array}$ & [37] \\
\hline Puerarin & PAMAM & Topical ocular & $\begin{array}{c}\text { Ocular } \\
\text { hypertension and } \\
\text { cataract }\end{array}$ & $\begin{array}{c}\text { Increased } \\
\text { bioavailability }\end{array}$ & [38] \\
\hline $\begin{array}{c}\text { Fluocinolone } \\
\text { acetonide }\end{array}$ & PAMAM G4-OH & Intravitreal injection & $\begin{array}{c}\text { Retinal } \\
\text { neuroinflammation }\end{array}$ & Reduced inflammation & [39] \\
\hline $\begin{array}{c}\text { Brimonidine and } \\
\text { timolol maleate }\end{array}$ & PAMAM hydrogel (G3) & Topical ocular & Glaucoma & Increased uptake & [40] \\
\hline $\begin{array}{c}\text { Brimonidine and } \\
\text { timolol }\end{array}$ & $\begin{array}{c}\text { Hybrid PAMAM } \\
\text { dendrimer }\end{array}$ & Topical ocular & Glaucoma & Increased uptake & [41] \\
\hline
\end{tabular}




\section{DENDRIMERS IN ORAL DELIVERY:}

Dendrimers serve as carriers for drugs in treating cancers for drugs administered through the oral route. Dendrimers proffer superior stability of drugs administered orally by encapsulating them and shielding them from gastric, intestinal enzyme degradation [42]. The stability of these G0 PAMAM conjugates in $50 \%$ liver homogenate was compared to that in $80 \%$ human plasma, showing the lactate ester linker gave prodrug of high stability in plasma with slow hydrolysis in liver homogenate; such conjugates may have potential in controlled release systems while using diethylene glycol as a linker gives conjugate that showed high chemical stability, but readily released drug in plasma and liver homogenate. So, these conjugations demonstrate potential as nanocarriers for the enhancement of oral bioavailability.

\section{DENDRIMERS IN PULMONARY DRUG DELIVERY:}

Pulmonary applications of dendrimers include pressurized metered-dose inhalers, soft mist inhalers, nebulizers, and dry powder inhalers [43]. Wangpradit O [49] described that G2, G2.5, and G3 of PAMAM dendrimers were assessed for pulmonary absorption of enoxaparin, an anticoagulant drug. Indirect estimation of enoxaparin was done by assessing the antifactory $\mathrm{Xa}$ activity and estimating the level of deep vein thrombosis estimated indirectly by determining the anti-factor $\mathrm{Xa}$ activity and analyzing the deep vein thrombosis prevention in a rodent. The results of the same study exposed that amine-terminated G2 and G3 PAMAM dendrimers could enhance pulmonary absorption of enoxaparin by $40 \%$. Also, the authors did not report any extensive damage done to the lungs. Negatively charged dendrimers with carboxyl end groups (G2.5) did not affect the bioavailability of enoxaparin. The above research article threw light on the usage of cationic surface-charged dendrimers in the pulmonary delivery of enoxaparin.

Kaminskas LM (Methotrexate-conjugated PEGylated dendrimers show differential patterns of deposition and activity in tumorburdened lymph nodes after intravenous and subcutaneous administration in rats, 2015)proved that PEGylated polylysine dendrimer, conjugated to doxorubicin, enhances drug exposure to lung metastases and improves cancer therapy, which means that these dendrimers have potential as inhalable chemotherapeutic nanomedicines [44]

\section{DENDRIMERS IN TARGETED DRUG DELIVERY:}

An attractive approach to treat few diseases like HIV, tuberculosis, malaria, and cancer 
is to target the drugs to the specific site of action, thereby, doses are required and side effects can be considerably reduced [45]. Dendrimers can form antibody or drug conjugates and can target them to specific receptors. Two kinds of targeted drug delivery- active targeting of drugs and passive targeting of composites can be exploited for efficacious delivery [46]. There is a need for targeted drug delivery to minimize the drug distribution, accumulation, and activity in healthy human cells.

[46] Narmani A studied the anti-cancer efficacy of oxaliplatin using a nanocarrier system with enhanced targeting efficacy towards folic acid receptor-expressing colorectal cancer cells in vitro. This system consisted of PAMAM dendrimers G4 imprinted with polyethylene glycol (PEG) and folic acid. Polyethylene glycation of polymeric nanoparticles is frequently applied to increase stability, and thus the half-life, as well as the non-immunogenic and non-antigenic properties. The PEGPAMAM nano-complex containing oxaliplatin was shown to have a superior cellular uptake in the SW480 cell line.

\section{DENDRIMERS AS DRUGS:}

Additionally, dendrimers themselves possess anti-inflammatory, anti-viral, and anti-microbial properties. Modified Poly (lysine) dendrimers with sulfonated naphthyl groups were reported to be used as antivirals mainly to counter the herpes simplex virus (HSV), PAMAM dendrimers when covalently altered with naphthyl sulfonate residues on the surface showed antiviral activity against Human Immuno Virus. This is thought to be by preventing virus capturing human healthy cells which in turn prevents replication of virus using reverse transcriptase and integrase enzymes at the advanced stage. Dendrimers of polypropylene imine type with tertiary alkylammonium groups attached with the surface have been found to have potent antibacterial biocides against gram-positive and gram-negative bacteria.

The polylysine dendrimers when attached with mannosyl surface groups are effective inhibitors for adhesion of E. coli to the horse blood cells in hemagglutination assay, acting as antibacterial too. Chitosandendrimer is used as antibacterial agents and also carriers in drug delivery systems.

\section{CONCLUSION:}

Dendrimers, being these multifaceted hyperbranched structures can aid in the augmentation of many pharmacokinetic and pharmacodynamic parameters that eventually results in the successful delivery of drugs to the site of action. Dendrimers possess many branches depending on the generation of dendrimers and have various functional groups attached to the exterior. 
This particular architectural trait of dendrimer can be exploited and can be used for the betterment of drug delivery systems. Synthesis of dendrimers generally can be either by convergent approach, divergent approach, click chemistry, or by lego chemistry. Exceptional challenges in building a dendrimer are hindering the usage of dendrimers and dendritic polymers extensively in the field of pharmaceutical drug delivery systems, though there are about 27,000 scientific reports and a similar number of patents on dendritic molecules. If only, dendrimers could be synthesized more easily in a simpler fashion or were easily available, the use of dendrimers would significantly assist the scientists of formulation and development division to use them extensively and benefit out of their numerous unique properties. Dendrimers themselves can act as drugs possessing anti-inflammatory, anti-viral, and anti-microbial properties. Dendrimers can act as wonder branched molecules as in targeted drug delivery, pulmonary drug delivery, and various other routes and modes of drug delivery. Further research can be focussed on the synergistic activity of dendrimers with few drugs.

\section{ACKNOWLEDGEMENTS:}

The authors wish to thank the management of Sarojini Naidu Vanita Pharmacy Maha
Vidyalaya for providing the necessary facilities to complete this write-up.

\section{CONFLICT OF INTEREST:}

None.

\section{REFERENCES:}

[1] Kaminskas L, McLeod V, Ascher D, Ryan G, Jones S, Haynes J, Trevaskis N, Chan L, Sloan E, Finnin B, Williamson M, Velkov T, Williams E, Kelly B, Owen D, Porter C. Methotrexate-Conjugated PEGylated Dendrimers Show Differential Patterns of Deposition and Activity in Tumor-Burdened Lymph Nodes after Intravenous and Subcutaneous Administration in Rats. Molecular Pharmaceutics. 2015;12(2):432-443.

[2] J. Rojo, R. Delgado. Dendrimers and Dendritic Polymers as Antiinfective Agents: New Antimicrobial Strategies for Therapeutic Drugs. Anti-Infective Agents in Medicinal Chemistry. 2007;6(3):151-174.

[3] Klajnert B, Bryszewska M. Dendrimers: properties and applications. Acta Biochimica Polonica. 2001;48(1):199-208.

[4] Tomalia D. The dendritic state. Materials Today. 2005;8(3):34-46.

[5] Tomalia D, Baker H, Dewald J, Hall M, Kallos G, Martin S, Roeck 
J, Ryder J, Smith P. A New Class of

Polymers: $\quad$ Starburst-Dendritic

Macromolecules. Polymer Journal. 1985;17(1):117-132.

[6] Fréchet J, Tomalia D. Dendrimers and other dendritic polymers. Chichester: Wiley; 2010.

[7] Newkome G, Moorefield C, Vögtle F. Dendrimers and dendrons. Weinheim: Wiley-VCH; 2003.

[8] Majoral J, Caminade A. Dendrimers Containing Heteroatoms ( $\mathrm{Si}, \mathrm{P}, \mathrm{B}$, Ge, or Bi). Chemical Reviews. 1999;99(3):845-880.

[9] Bosman A, Janssen H, Meijer E. About Dendrimers: Structure, Physical Properties, and Applications. Chemical Reviews. 1999;99(7):1665-1688.

[10] Tomalia D, Hedstrand D, Ferritto M. Comb-burst dendrimer topology: new macromolecular architecture derived from dendritic grafting. Macromolecules. 1991;24(6):1435-1438.

[11] Zheng Y, Li S, Weng Z, Gao C. ChemInform Abstract: Hyperbranched Polymers: Advances from Synthesis to Applications. ChemInform. 2015;46(32)

[12] Grayson S, Fréchet J. Convergent Dendrons and Dendrimers: from
Synthesis to Applications.

Chemical Reviews.

2001;101(12):3819-3868.

[13] Tomalia D, Fréchet J. Discovery of dendrimers and dendritic polymers: A brief historical perspective*. Journal of Polymer Science Part A: Polymer Chemistry. 2002;40(16):27192728.

[14] Mazumder A, Davis J, Rangari V, Curry M. Synthesis, Characterization, and Applications of Dendrimer-Encapsulated ZeroValent $\mathrm{Ni}$ Nanoparticles as Antimicrobial Agents. ISRN Nanomaterials. 2013;2013:1-9.

[15] Ziemba B, Matuszko G, Bryszewska M, Klajnert B. Influence of dendrimers on red blood cells. Cellular and Molecular Biology Letters. $2012 ; 17(1)$.

[16] de Gennes P, Hervet H. Statistics of « starburst » polymers. Journal de Physique Lettres. 1983;44(9):351-360.

[17] Mansfield M, Klushin L. Monte Carlo studies of dendrimer macromolecules. Macromolecules. 1993;26(16):4262-4268.

[18] Bhalgat M, Roberts J. Molecular modeling of polyamidoamine 
(PAMAM) $\quad$ Starburst $^{\mathrm{TM}}$

dendrimers. European Polymer

Journal. 2000;36(3):647-651.

[19] Grayson S, Fréchet J. Convergent Dendrons and Dendrimers: from Synthesis to Applications. Chemical Reviews. 2001;101(12):3819-3868.

[20] Tomalia D, Naylor A, Goddard W. Starburst Dendrimers: MolecularLevel Control of Size, Shape, Surface Chemistry, Topology, and Flexibility from Atoms to Macroscopic Matter. Angewandte Chemie International Edition in English. 1990;29(2):138-175.

[21] Caminati G, Turro N, Tomalia D. Photophysical investigation of starburst dendrimers and their interactions with anionic and cationic surfactants. Journal of the American Chemical Society. 1990;112(23):8515-8522.

[22] Prajapati S, Maurya S, Das M, Tilak V, Verma K, Dhakar R. DENDRIMERS IN DRUG DELIVERY, DIAGNOSIS AND THERAPY: BASICS AND POTENTIAL APPLICATIONS. Journal of Drug Delivery and Therapeutics. 2016;6(1).

[23] Mulder A, Huskens J, Reinhoudt D. Multivalency in supramolecular chemistry and nanofabrication. Organic \& Biomolecular Chemistry. 2004;2(23):3409.

[24] Kaminskas L, Pires D, Ascher D. dendPoint: a web resource for dendrimer pharmacokinetics investigation and prediction. 2021.

[25] Jahromi S, Palmen J, Steeman P. Rheology of Side Chain Dendritic Polymers. Macromolecules. 2000;33(2):577-581.

[26] Pandita D, Poonia N, Kumar S, Lather V, Madaan K. Dendrimers in drug delivery and targeting: Drug-dendrimer interactions and toxicity issues. Journal of Pharmacy and Bioallied Sciences. 2014;6(3):139.

[27] Boyd B, Bergström C, Vinarov Z, Kuentz M, Brouwers J, Augustijns P, Brandl M, Bernkop-Schnürch A, Shrestha N, Préat V, Müllertz A, Bauer-Brandl A, Jannin V. Successful oral delivery of poorly water-soluble drugs both depends on the intraluminal behavior of drugs and of appropriate advanced drug delivery systems. European Journal of Pharmaceutical Sciences. 2019;137:104967.

[28] Jannin V. Complex Interplay Between Solubilization, Digestion, Supersaturation and Absorption of 
Poorly Soluble Drugs with Lipid-

Based Formulations. Current Drug

Delivery. 2018;15(6):749-751.

[29] Gerrits L, Hammink R, Kouwer P. Semiflexible polymer scaffolds: an overview of conjugation strategies. Polymer Chemistry. 2021;12(10):1362-1392.

[30] Synthesis of poly(amidoamine)poly(ethyleneglycol)poly(amidoamine) and preparation of its hydrogel solution containing doxorubicin. Journal Of Chinese Pharmaceutical Sciences. 2019;28(5):316-328.

[31] Ding L, Lyu Z, Dhumal D, Kao C, Bernard M, Peng L. Dendrimerbased magnetic resonance imaging agents for brain cancer. Science China Materials. 2018;61(11):1420-1443.

[32] Idris A, Mamba B, Feleni U. Poly (propylene imine) dendrimer: A potential nanomaterial for electrochemical application. Materials Chemistry and Physics. 2020;244:122641.

[33] Paraskevi P. Dendrimers as drug delivery systems. Frontiers in Pharmacology. 2010;1.

[34] Kolhe P. Drug complexation, in vitro release and cellular entry of dendrimers and hyperbranched polymers. International Journal of Pharmaceutics. 2003;259(12):143-160.

[35] Poudel D, Taylor R. A Model for Late-Stage Modification of Polyurethane Dendrimers Using Thiol-Ene Click Chemistry. ACS Omega. 2021;6(18):12375-12381.

[36] Gaikwad A, Ahire K, Gosavi A, Salunkhe K, Khalkar A. Gaikwad Abhijeet R. Phytosome as a Novel Drug Delivery System for Bioavailability Enhancement of Phytoconstituents and its Applications: A Review. Journal of Drug Delivery and Therapeutics. 2021;11(3):138-152. [37] Kesharwani P, Jain K, Jain N. Dendrimer as nanocarrier for drug delivery. Progress in Polymer Science. 2014;39(2):268-307.

[38] Wangpradit O, Adamcakova-Dodd A, Heitz K, Robertson L, Thorne P, Luthe G. PAMAM dendrimers as nano carriers to investigate inflammatory responses induced by pulmonary exposure of PCB metabolites in Sprague-Dawley rats. Environmental Science and Pollution Research. 2015;23(3):2128-2137.

[39] Arima H, Motoyama K, Higashi T. Potential Use of Polyamidoamine 
Dendrimer Conjugates with Cyclodextrins as Novel Carriers for siRNA. Pharmaceuticals. 2011;5(1):61-78.

[40] Cheng Y, Xu Z, Ma M, Xu T. Dendrimers as Drug Carriers: Applications in Different Routes of Drug Administration. Journal of Pharmaceutical Sciences. 2008;97(1):123-143.

[41] Patri A, Kukowskalatallo J, Bakerjr J. Targeted drug delivery with dendrimers: Comparison of the release kinetics of covalently conjugated drug and non-covalent drug inclusion complex. Advanced Drug Delivery Reviews. 2005;57(15):2203-2214.

[42] Nasr M, Najlah M, D'Emanuele A, Elhissi A. PAMAM dendrimers as aerosol drug nanocarriers for pulmonary delivery via nebulization. International Journal of Pharmaceutics. 2014;461(12):242-250.

[43] Dwivedi D, Singh A. DENDRIMERS: A NOVEL CARRIER SYSTEM FOR DRUG DELIVERY. Journal of Drug Delivery and Therapeutics. 2014;4(5).

[44] Winnicka K, Wroblewska M, Wieczorek P, Sacha P,
Tryniszewska E. The Effect of PAMAM Dendrimers on the Antibacterial Activity of Antibiotics with Different Water Solubility. Molecules. 2013;18(7):8607-8617.

[45] Saovapakhiran A, D’Emanuele A, Attwood D, Penny J. Surface Modification of PAMAM Dendrimers Modulates the Mechanism of Cellular Internalization. Bioconjugate Chemistry. 2009;20(4):693-701.

[46] Narmani A, Kamali M, Amini B, Salimi A, Panahi Y. Targeting delivery of oxaliplatin with smart PEG-modified PAMAM G4 to colorectal cell line: In vitro studies. Process Biochemistry. 2018;69:178-187.

[47] Chauhan AS, Jain NK, Diwan PV, Khopade AJ. Solubility enhancement of indomethacin with poly(amidoamine) dendrimers and targeting to inflammatory regions of arthritic rats. J Drug Target. 2004;12(910):575-83

[48] Gajbhiye, Virendra \& Kumar, Palanirajan \& Sharma, Ajay \& Agarwal, A \& Asthana, Abhay \& Jain, Narendra. Dendrimeric Nanoarchitectures Mediated 
Transdermal and Oral Delivery of

Bioactives. Indian journal of

pharmaceutical sciences 2008; 70 :

431-9.

[49] Wangpradit O, Adamcakova-Dodd

A, Heitz K, Robertson L, Thorne

PS, Luthe G. PAMAM dendrimers

as nano carriers to investigate

inflammatory responses induced

by pulmonary exposure of PCB

metabolites in Sprague-Dawley

rats. Environ Sci Pollut Res Int.

2016;23(3):2128-37 